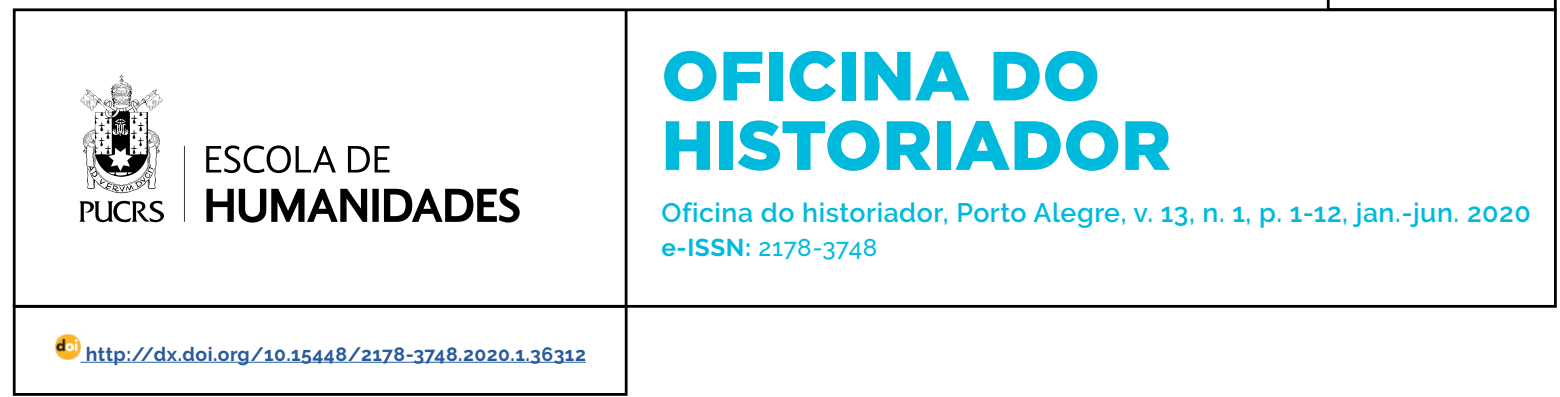

DOSSIÊ ARQUEOLOGIA E ONTOLOGIA

\title{
Conceitos outros: as coisas e a Virada Ontológica
}

\author{
Concepts other: things and the Ontological Turn
}

\author{
Antonio Carlos Soares ${ }^{1}$ \\ orcid.org/0000-0002-1936-5945 \\ soares_rs@hotmail.com
}

Recebido em: 10 nov. 2019 Aprovado em: 16 jan. 2020. Publicado em: 14 jun. 2020.
Resumo: Este texto pretende discutir as possibilidades de uma abordagem ontográfica sobre a problematização das coisas, ou aquilo que chamamos de "cultura material". Uma abordagem inserida no contexto da chamada Virada Ontológica, da qual emergem os estudos sobre a alteridade que a partir das coisas, neste caso, produzidas pelo outro, busca "traduzir" em conceitos a ontologia outra e comparar as diferenças conceituais suscitadas durante o processo. Uma comparação translativa entre conceitos produzidos por ambos os agentes teóricos: o nativo e o antropólogo. Os estudos sobre as coisas têm se voltado para concepções mais literalistas acerca, inclusive, da própria definição de "coisa" nos últimos anos, sobretudo quando há o envolvimento de dois ou mais "mundos" na equação. Na Antropologia, o debate sobre a Ontological Turn ocorre com maior velocidade e intensidade, voltando-se para o cerne da própria disciplina, abalando alguns fundamentos modernos que formataram o próprio fazer antropológico. É a partir desse debate, ainda em andamento, que a disciplina que utiliza as coisas como fonte, a Arqueologia, vem buscando reorientar suas análises sobre as coleções resultantes de suas pesquisas.

Palavas-chave: Cultura Material. Arqueologia. Ontologia.

Abstract: This paper discusses the possibilities of a ontografic approach to the questioning of things, or what we call "material culture". An embedded approach in the context of the call Ontological Turn, from the study of otherness that from the things in this case produced by the other, seeks to "translate" into concepts ontology another and compare the raised conceptual differences during the process. A translative comparison between concepts produced by both theoretical agents: the native and the anthropologist. Studies of things in recent years have turned to more literalistic conceptions of even the very definition of "thing". especially when two or more "worlds" are involved in the equation. In Anthropology, the debate on the Ontological Turn occurs with greater speed and intensity, turning to the core of the discipline itself, shaking some modern foundations that formed the own doing anthropological. It is from this debate, still in progress, that the discipline that uses things as its source, Archaeology, has been seeking to refocus its analysis on the collections resulting from its research.

Keywords: Material Culture. Archaeology. Ontology.

\section{Introdução: "cultura material" como episteme}

A história da Arqueologia, assim como das Ciências Humanas, é marcada por muitas "viradas", que ao longo do tempo, foram construindo-a como um campo disciplinar que utiliza a "cultura material como objeto de sua episteme". Falar de Arqueologia, no meio acadêmico, é falar em estudar as sociedades em todos os seus aspectos e suas dimensões, a partir da cultura material. Portanto, propor uma história da Arqueologia passa por propor uma história da conceituação de "cultura material" ao longo do tempo e do espaço, descrevendo o contexto do desenvolvimento da Ciência
Artigo está licenciado sob forma de uma licença Creative Commons Atribuição 4.0 Internacional. 
Arqueológica enquanto campo disciplinar. Se considerarmos subsumidas no conceito de "cultura material" as perspectivas cronologicamente situadas e historicamente contextualizadas, que hoje norteiam o fazer arqueológico, sobretudo as "interpretações" constantes nos registros arqueológicos, perceberemos que o conceito "cultura material" e sua história, constituem-se em um sistema produção de conhecimentos sobre as coisas. Uma episteme! Sendo assim, a construção de "cultura material" enquanto conceito, revela-se como a própria epistemologia acerca das "coisas antropisadas". Outra pequena observação que se pode levantar sobre ser a "cultura material" o objeto epistemológico da Arqueologia, diz respeito ao dualismo moderno que coloca em oposição assimétrica os "sujeitos" e "objetos", tornando o primeiro ativo na produção e nas relações sociais e, o segundo, passivo da ação do primeiro. Considerar as coisas como "objetos" passivos, não participantes do meio social, é ignorar seus aspectos relacionais e de protagonismo social.

Como demonstra Lima (2011) ao apontar a cultura material como "a dimensão concreta das relações sociais". Historiando o conceito de cultural material a partir da perspectiva dos cânones da Arqueologia, a autora aponta, inicialmente, para a influência do evolucionismo do século XIX no surgimento do primeiro paradigma formal para a disciplina, surgido no início do século XX. Para o histórico-culturalismo, a cultura material é entendida como reflexo passivo da cultura, que por sua vez, é conceituada como "um conjunto de normas, valores, ideias, prescrições, e regras partilhados entre um determinado grupo". Assim, os artefatos portariam significados que the seriam inerentes (LIMA, 2011, p. 13).

Em crítica ao paradigma histórico-culturalista, no contexto de pós-guerra, surge a perspectiva de cultura material como resposta adaptativa, não biológica, às pressões do meio ambiente sofridas pelos grupos humanos. Liderados por Lewis Binford, os processualistas buscaram compreender a dinâmica dos processos culturais por meio de análises quantitativas exaustivas para identificar padrões no comportamento humano e, por conseguinte, na produção material (LIMA, 2011, p. 14-15). Talvez o movimento mais significativo para a conceituação da cultura material tenha ocorrido no contexto da Virada Linguistica, que na Arqueologia, segundo a autora, após a década de 1980, ocorre pela influência do pós-estruturalismo, afinado com a teoria social pós-moderna, e que considera, "assim como a linguagem, a cultura material um sistema estruturado de signos, de modo que ela pode ser considerada como um texto" (LIMA, 2011, p. 19). Para os autodenominados pós-processualistas, como Christopher Tilley e Ian Hodder, a cultura material (textos materiais) pode ser lida de maneiras diferentes, estando essa leitura implicitamente aberta para múltiplas interpretações. A cultura material, como signo, é agente ativo na ordenação da vida social, não tendo significados inerentes. Os significados são construidos em seus contextos. Segundo a autora, essa perspectiva pós-processual, que incluiu os aspectos simbólicos e cognitivos nos estudos da cultura material, abriu caminho para a dimensão sensorial. Fundada na fenomenologia, essa perspectiva aponta que a relação com a materialidade passa pelas sensações e percepções, e que ao serem informadas por sentidos, se torna "uma experiência da consciência" (LIMA, 2011, p. 20). Neste contexto pós-processualista é que surgem os novos materialistas, incluindo a noção de agência (agency) das coisas por antropólogos como Alfred Gell e Bruno Lattour, e as múltiplas atribuições de significados que vão se modificando ao longo da história de vida dos objetos, com antropólogos como Marshal Sahlins, Daniel Miller, Mary Douglas, em uma perspectiva que associa o marxismo, o estruturalismo e a semiótica.

Com este texto, pretendemos discutir as possibilidades de uma abordagem ontográfica sobre a problematização das coisas, ou o que chamamos de "cultura material". Uma abordagem inserida no contexto da chamada Virada Ontológica, da qual emergem os estudos sobre a alteridade que, no nosso caso, a partir da "cultura material", produzidas pelo outro, busca "traduzir" em conceitos essa alteridade ontológica e comparar as diferenças conceituais suscitadas durante o processo entre as comparações de ambos os agentes teóricos: o nativo e o antropólogo. Para tanto, trazemos os 
estudos de Viveiros de Castro (1996, 2002, 2006, 2014), conhecidos por perspectivismo amerindio, que propõe "levar a sério o que diz o nativo", abolindo a narrativa clássica "representacionalista" da antropologia, considerando as narrativas ameríndias como antropologias. Essa proposta de simetria entre o que, tradicionalmente, era visto como uma relação sujeito-objeto ou "sujeitos passivos" coloca a relação entre o antropólogo e o nativo como uma relação sujeito-sujeito, ambos agentes teóricos. O trabalho do antropólogo, dessa forma, não é mais a descrição representacional do seu objeto de pesquisa, ou dos "sujeitos passivos", mas o de comparar antropologias, por meio de uma comparação translativa antropologicamente controlada, tendo a noção de "equívoco" como meio de reconceitualizar os conceitos práticos e discursivos nativos (VIVEIROS DE CASTRO, 2004, p. 4).

Os estudos de Viveiros de Castro foram significativos para uma nova perspectiva sobre a Arqueologia, desencadeando uma série de críticas teóricas que redundaram em possibilidades metodológicas para a "cultura material". Destaco aqui os trabalhos de Almiria Henare (2007), Martin Holbraad (2003, 2007, 2012) e Benjamin Albert e Yvonne Marshal (2009) que norteiam, nesse trabalho de reflexão, as possibilidades de um método ontográfico, ou de uma arqueologia que leva a sério a alteridade ontológica.

\section{As coisas e a Virada Ontológica}

A abordagem antropológica tradicional sobre a cultura, desenvolvida ao longo do último século, produziu a interpretação representativa, ou seja, uma visão epistemológica sobre as questões ontológicas. Essa abordagem clássica, "representacionista", supôs uma Antropologia como a construção de sistema de conhecimentos (episteme) acerca das formas como as diferentes culturas representam o mundo - ou a natureza descrita pelas ciências naturais. A unidade natural e a multiplicidade cultural, ou seja, o multiculturalismo, é expresso como resultante do projeto moderno, cartesiano, pelo qual se engendraram as interpretações epistemológicas da Antropologia.

Viveiros de Castro lançou as bases para materializar as discussões acerca das limitações das interpretações epistemológicas, ao perceber um conjunto de ideias e de práticas entre os nativos americanos, denominando-as como cosmologia, pela qual supõe uma unidade espiritual e uma diversidade corpórea. Segundo o autor, essa cosmologia concebe um universo povoado por diferentes agências subjetivas, humanas e não humanas, dotadas de um mesmo conjunto genérico de capacidades cognitivas e volitivas, mesma alma, que implica a posse de conceitos semelhantes. Os individuos da mesma espécie se veem, em particular, como seres humanos se veem, vendo seus aspectos comportamentais e corporais como na cultura humana. O que muda, de uma espécie para outra são os conceitos correlatos objetivos. Como no exemplo ameríndio, reproduzido por Viveiros de Castro em seus trabalhos, que relata a informação de que "quando a onça bebe sangue, ela vê cauim" (1996, p. 127). Pela abordagem epistemológica, com reminiscências colonialistas, o antropólogo procuraria entender os motivos pelos quais o sangue representaria cauim, recorrendo a mitos, analogias etc. O que Viveiros de Castro defende é que essa assertiva ameríndia seja tratada como conhecimento teórico em simetria ao conhecimento ocidental, e que o problema seja ontológico, isto é, que se busque discutir e comparar o conceito de sangue e cauim, até mesmo o conceito de onça, reconhecendo a radical alteridade implicada na mobilização desses conceitos pelo nativo. Levar a sério o que diz o nativo, seria reconhecer o seu relato inserido no "mundo outro", não apenas uma "visão de mundo" a ser representada no discurso antropológico a partir da episteme inserida na ontologia ocidental e moderna, que via de regra, considera declarações outras como metonímias, ou alegorização da "realidade". Enquanto a nossa ontologia, euroamericana moderna, é fundada na unidade da natureza e da multiplicidade de culturas, na ontologia ameríndia, segundo o autor, há a unidade espiritual e a multiplicidade corpórea, em outras palavras, uma cultura e múltiplas naturezas. Neste sentido, o perspectivismo não é um relativismo 
subjetivo ou cultural como conhecemos, é um multinaturalismo (VIVEIROS DE CASTRO, 2004, p. 6).

Desta forma, fazendo uma reflexão a respeito, reconhecendo a literalidade da afirmação nativa como conhecimento, poderíamos nos aproximar do entendimento expresso na afirmação ameríndia fazendo um pequeno exercício empático metafísico. Uma tentativa de "pensar como", sem deixar de reconhecer a falibilidade que nos coloca na zona do "equívoco": a onça só bebe sangue porque é onça, e o faz da mesma maneira que os humanos fazem quando bebem cauim. A onça habita a natureza das onças, vendo e se relacionando como os outros seres e com a própria natureza da mesma maneira que os ameríndios veem e o fazem. Em termos linguísticos analíticos, a onça beber sangue e o homem beber cauim não "teria" o mesmo significado, mas "seria" o mesmo significante na ontologia ameríndia, desde que os corpos estejam situados na ordem apresentada. Se a onça de fato bebesse o cauim, seria outra "coisa"!

O perspectivismo amerindio colocado desta forma por Viveiros de Castro, provocou - e provoca - inúmeras questões sobre o fazer antropológico. "O que acontece quando se leva o pensamento nativo a sério?" (2002, p. 129, grifo nosso). Significa, em tese e na prática, descolonizar o pensamento antropológico ocidental. Reconhecer na ontologia outra a produção de uma "episteme" distinta da ontologia ocidental, portanto, portadora de conceitos distintos, suigeneris, (uma episteme outra?) para os quais seriam possiveis comparações translativas.

Para a materialidade, levar a sério a ontologia outra, significa reconhecer o compromisso ontológico, ou seja, os mundos outros. Evitar as representações epistemológicas, a redução das articulações a meras "visões de mundo", e passar a considerar as afirmações dos nativos como afirmações de "mundos" ou naturezas distintas. Dessa forma, "pensar através das coisas", consiste em identificar "mundos" diferentes nas "coisas" e criar conceitos analíticos como recurso para pensar o mundo outro (HENARE et al., 2007, p. 18). Seguindo na mesma direção, Holbraad (2003, 2012), aponta para a necessidade de reconhecer as ideias ameríndias como conceitos de uma alteridade intencional. Entretanto para que se possa tornar a intenção nativa inteligivel à ontologia ocidental - de onde e para quem falamos aqui para evitar uma posição de aporia, é necessário criar conceitos a partir dos conceitos nativos (para nós igualmente novos). Criar o novo a partir do que já existe (HOLBRAAD, 2003, p. 43). A proposta, que Holbraad nomeia como "método ontográfico", não é se apropriar dos conceitos nativos, mas de produzir equivalentes aproximados, a fim de mapear as premissas ontológicas do discursos nativos à luz dos nossos conceitos (HOLBRAAD, 2003, p. 44-45). Semelhante ao proposto por Viveiros de Castro (2004) sugerido como "método da equivocação controlada", que coloca a noção do equivoco residente nas diferenças translativas entre os conceitos nativos e ocidentais, sendo o fazer antropológico trabalhar (controladamente) sobre esses equívocos. Alberti e Marshall (2009), apontam para o risco da relativização das assertivas ontológicas no uso do termo "ontologias", que pode não ser suficiente para quebrar os velhos hábitos mentais das representações metafóricas, não reconhecendo a literalidade nos conceitos nativos. Dizem que no modelo perspectivista de Viveiros de Castro, relacionar é diferir, que a tradução é uma operação de produção de diferenças, que conecta os dois discursos (ocidental e nativo) à medida exata que eles não estão dizendo a mesma coisa sobre conceitos sinônimos (ALBERTI; MARSHALL, 2009, p. 347).

\section{Método ontográfico}

Nos trabalhos dos arqueólogos ou dos antropólogos da materialidade, vinculados aos estudos ontológicos, percebemos o recorrente uso do termo "coisas" para o que ora chamamos de "cultura material", "artefatos" ou "objetos". O conceito de "cultura material" é epistemologicamente carregado, sendo o uso do termo "coisas" portador de uma menor bagagem teórica. Assim, o termo "coisa" pode ser usado de forma analítica (clássica) e de forma heurística. A primeira, a forma clássica, implica em um repertório classificatório, a segunda, a heuristica, serve para moldar coisas, usado como sinônimo esvaziado para "cultura material", 
"artefato" ou "objeto". Esse pressuposto está vinculado ao novo impulso dentro da antropologia (e arqueologia) de "desenvolvimento de filtros cada vez mais diferenciados pelos quais passam fenômenos como canais para a produção de conceitos através de compromissos com as coisas" (HENARE et al., 2007, p 8, tradução nossa). Alberti e Marshall (2009) capturam a ideia de "conceitualidade aberta", por onde a produção teórica seja contínua em vez de prédeterminada. As "coisas" encontradas em campo, determinam novas estruturas e teorias analíticas como resultado do encontro, tomando as coisas em campo como literalmente se apresentam, em uma espécie de "essencialismo radical" ou um "anti-representacionismo epistemológico" (ALBERTI; MARSHALL, 2009, p. 349).

Neste ponto, torna-se construtivo a exposição de um exemplo mencionado por Henare et al. (2007), que fala sobre a afirmação feita por adivinhos Ifá, em Havana, informantes de Martin Holbraad, que aponta o poder do pó, aché, como um conceito ou coisa não isolável, afirmando que o pó é poder e vice-versa. Holbraad (2007) mostra que recusar a priori a separação de coisa e conceito, permitiu "pensar através de" um novo conceito como "pó-poder", para demonstrar os aspectos da ontologia Ifá. Levar a sério a alteridade ontológica, nesse caso, consistiu em pensar em conceitos de pó e de poder de maneira aberta. De qual pó e de qual poder falam os praticantes de Ifá? A abordagem clássica da antropologia levaria a conclusões do tipo "eles acreditam que o pó é poder", e a tarefa antropológica seria de buscar as relações entre o pó e o poder para, assim justificar a afirmação. No entanto, os informantes de Holbraad atestam que o pó não é apenas poderoso, ele é poder. $O$ pó Ifá, como "coisa" tomada de maneira heuristica, traz a conexão com o poder de forma imanente. Se nos parece estranho, ou parece um problema de interpretação conceitual, ou uma "bizarrice", que na ontologia ocidental dominante não faça sentido a afirmação de que pó seja poder, e poder seja pó, é um problema "nosso", não "deles". Seria assim, um problema translativo, cujos correlatos objetivos ocidentais não correspondem aos mesmos conceitos homonímicos Ifá de pó e poder. Ao encontrar em campo uma "coisa", Holbraad, desenvolveu a teoria a partir do encontro, in loco, moldando uma "coisa" nova sobre os conceitos já existentes, o "pó-poder".

Outra demonstração de um método ontográfico, ou pelo menos, diretamente associado, é o classificado por Alberti e Marshall (2009) como uma extensão da discussão teórica, que avalia as vasilhas biomórficas de La Candelaria, no Noroeste da Argentina, do primeiro milênio da era cristã. São vasos que apresentam características anatômicas exageradas, formas hibridas humanas, aves-humanas, animais e protuberâncias em forma de mamilos. Esses vasos foram recuperados, em grande parte, por colecionadores, portanto com poucos dados contextuais. Devido à relação geográfica, esse material pode ser lido como relacionado com a cosmologia amazônica, por analogia. Citando Lévi-Strauss, e o mito amazônico difundido de um tempo mítico de transição, quando os humanos e os animais ainda não eram claramente distinguidos, os autores abordam que se tomados pela lógica "representacionista", esses vasos poderiam ser interpretados como representações dos mitos amazônicos, de conotações ritualísticas. Também corroboraria com essa abordagem a ideia de "corpos desorganizados", subjacente no perspectivismo amerindio de Viveiros de Castro. "Uma abordagem representacionalista considera a coisa como veículo de signo, revelando um conjunto de crenças culturais que podem ser lidas a partir dela" (ALBERTI; MARSHALL, 2009, p. 350, tradução nossa). Esta seria uma abordagem pelas "visões de mundo", mas a abordagem interessante aos autores é a que leva a alteridade ontológica a sério, uma abordagem pelos "mundos". Desta forma, o primeiro procedimento foi o esvaziamento de significados considerando-os como "coisa", como em um encontro inicial. Assim, considerá-los a partir de um novo conceito, assumindo a alteridade ontológica. Nem coisa-significante (pote) nem significado (corpo), seriam "corpo-pote" (body-pot).

Os autores, a partir de uma abordagem literalista, concebendo a estrutura teórica in loco, buscaram entender o que são os corpos-potes, não o que eles representam. A partir de uma possibilidade teórica, 
que considera o conceito de "corpo cronicamente instável", das pesquisas de Aparecida Vilaça sobre as afirmações dos Wari, no noroeste da Amazônia, que argumentam que o esqueleto serve para "escorar" o corpo, impedindo de adquirir outra forma, portanto, outra perspectiva do mundo. Combinando a teoria da identidade corpórea do perspectivismo de Viveiros de Castro com a teoria de Tim Ingold que materiais são "fluxos" e propriedades "históricas", associando com a teoria de Karen Barad de que a matéria é inerentemente indeterminada, os autores afirmam que os volumes e as formas anatômicas exageradas das cerâmicas não "representam" nada, apenas participam de uma preocupação constante da instabilidade corpórea (ALBERTI; MARSHALL, 2009, p. 352). Seriam, nessa possibilidade analítica, pontos de estabilidade material sobre um cenário ontológico fundado na concepção de instabilidade corpórea.

\section{A casa dos índios: uma possibilidade teórica}

Apresento o caso da "casa dos índios" do Museu Arqueológico do Rio Grande do Sul (Marsul), como uma possibilidade de aplicação dos preceitos teóricos levantados neste texto. Uma possibilidade metodológica sobre os conceitos que podem ser ontologicamente situados. Pode ser considerado um exemplo que evoca a alteridade ontológica o fato de encontrar uma casa típica Mbyá Guarani instalada no pátio de um museu ${ }^{3}$. O inicial estranhamento, anos depois a curiosidade e a necessidade profissional, me instigaram a buscar as circunstâncias que resultaram na instalação daquela estrutura naquele espaço específico. A "casa dos índios" do Marsul, pode ser encarada como resultado material de um projeto, "Projeto Vida de Índio", que no início dos anos 2000 objetivou a integração entre o público frequentador do museu e as comunidades Mbyá Guarani da região. A fim de promover a sustentabilidade daqueles grupos por meio do fomento ao comércio do artesanato, elemento central de interesse do projeto, colocado no contexto das discussões acerca das "comemorações" dos quinhentos anos do "descobrimento" e seus resultados, o Projeto Vida de Índio cumpriu um papel de promover um protagonismo indigena outro. ${ }^{4}$

Figura 1 - Casa dos índios (Casa temática Mbyá Guarani) em 2003

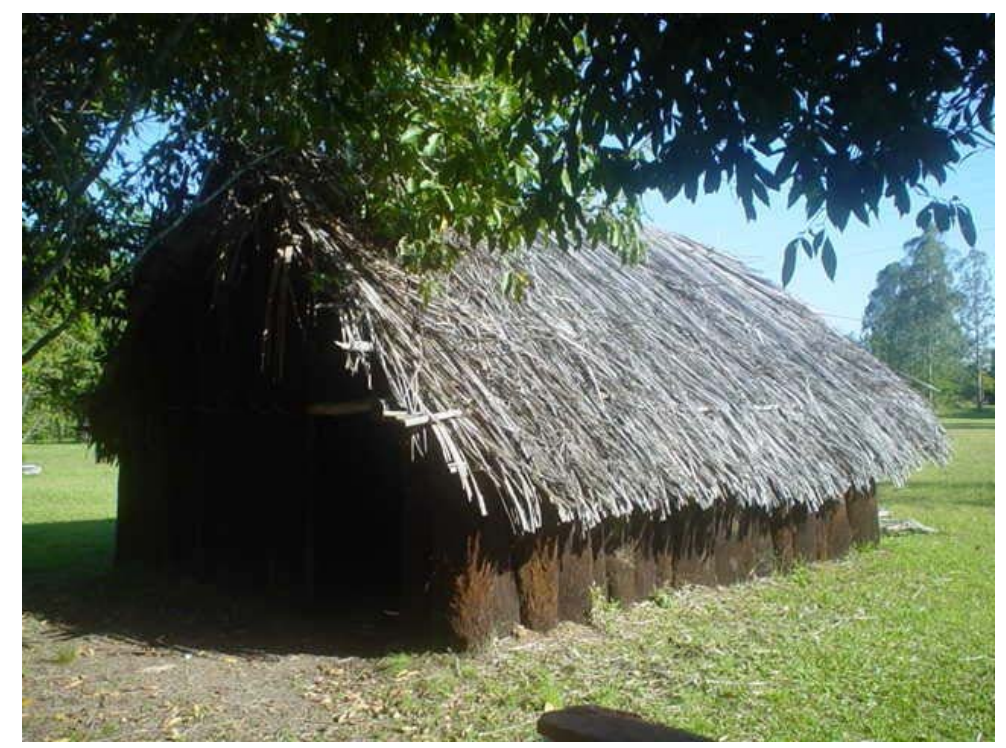

Fonte: Acervo Marsul.

\footnotetext{
3 Para ver sobre, SOARES, Antonio C. Casa dos Índios: a história de vida de um artefato. Mouseion, Canoas, n. 31, p. 89-104, 25 fev. 2019 . UNILASALLE, que demonstra a instalação de uma casa Mbyá Guarani no pátio do Museu Arqueológico do Rio Grande do Sul, MARSUL, em Taquara/ RS, abordando a história de vida da casa, isto é, as muitas significações assumidas ao longo do tempo, e sob ambas perspectivas ontológicas. 4 Protagonismo outro, como dizem Santos e Felippe (2017), a partir do qual interpreta-se as ações indigenas não apenas como reações às ações outras - colonial - considerando elementos na documentação, em geral, desprezados em estudos anteriores, construindo uma visão mais simétrica sobre a interação no contexto colonial, conferindo aos indígenas a condição de sujeitos/agentes de sua própria história. Uso o termo outro como complemento conceitual para situar a percepção a partir da alteridade ontológica.
} 
A casa foi encomendada e paga pela equipe do Marsul (ver Figura 1). Sua estrutura feita em eucaliptos, vedações laterais (paredes) em xaxim, cobertura de taquara batida, toda amarrada com cipós, aparentemente, tal como as casas no tekoá dos seus construtores. No entanto, de acordo com os registros na documentação e com depoimentos, a "Casa dos Índios"5, não foi utilizada como habitação, nem mesmo durante a estadia dos índios no Marsul, ao longo do mês de abril de 2002, quando foi construida pela comunidade Mbyá Guarani do Campo Molhado, (Tekoá Nhüu Porã). Segundo a professora Zilá Kolling, o que pode ser corroborado pelo acervo fotográfico, todos os Mbyá ficaram alojados no prédio do museu (KOLLING, 2018).

Esse fato nos leva a refletir sobre a condição de "casa", dessa estrutura que ora denominamos "casa dos indios". A casa enquanto produto Mbyá, certamente é carregada de simbolismos, tanto para a ontologia ocidental, os juruá, quanto para a comunidade que a produziu, os Mbyá. Faz parte da estrutura social e do sistema cultural do mundo ocidental (assim como em qualquer ontologia) atribuir valores simbólicos aos objetos, como também diz Pierre Bourdieu (2007) que "o poder simbólico é um poder de construção da realidade que tende a estabelecer uma ordem gnoseológica: o sentido imediato do mundo (e, em particular, do mundo social)" (2007, p. 9). Dessa extensão simbólica, não escapam os objetos mercantis produzidos pelo capitalismo como descreve Marshall Sahlins (2007) referenciando Karl Marx. No capitalismo, quando da produção mercadológica, as coisas são carregadas de valor simbólico pelo valor do uso. "Sem o consumo, o objeto não se completa como produto: uma casa que permaneça desocupada não é uma casa" (SAHLINS, 2007, p. 182).

A casa dos índios, nesse aspecto, e nesta etapa da sua vida, foi uma mercadoria encomendada.
Feita, a principio, para o uso do Marsul, não para o uso indigena. Ainda que as intenções declaradas na documentação, no projeto, nas planilhas e nos ofícios, assim como na entrevista, que demonstram as finalidades temáticas pretendidas para a casa, como espaço expositivo, espaço para oficinas e venda de artesanato. Essas finalidades têm relação com a preocupação do Marsul para com a comunidade Mbyá Guarani. Desta forma, a casa índios configura-se uma materialização das intenções da equipe do museu que, no extremo, também se soma o desejo de expor um bem cultural aos seus visitantes. Um artefato!

Mas sob a perspectiva da alteridade ontológica, dos Mbyá, mesmo que ainda não haja entrevistas com os construtores ${ }^{7}$, podemos buscar nas etnografias especificas realizadas ainda que essas se apresentem sob o enfoque epistemológico - indicações de como aquela estrutura seria conceituada pelos Mbyá. Desta forma, Prudente (2007), quando estudou em sua dissertação de mestrado o modelo construtivo das casas tradicionais Mbyá Guarani, as oó, feitas em xaxim no Tekoá Nhüu Porã (Campo Molhado), localizada entre os municipios de Maquiné, Riozinho e Caraá, mesma comunidade que produziu a casa dos índios do Marsul, apontando a originalidade, afirma que esse modelo construtivo (com o xaxim) foi introduzido a partir de 1995. relacionado à chegada na região de famílias Mbyá provenientes de Missiones, na Argentina. Uma casa Mbyá é uma "representação" do Tekoá, e seus materiais são sagrados, como relatou o cacique Morinico, sendo seus pilares centrais os homens, os pilares externos seriam as mulheres, as vigas de cobertura seriam as crianças e o centro não visivel seria o karai - liderança espiritual. Nesse mesmo centro não visivel ao olho dos não indigenas é onde também se localiza a espécie arbórea sagrada - o cedro, segundo a cosmologia Mbyá (PRUDENTE, 2007, p. 69).

\footnotetext{
5 Denominação popular que utilizei como forma de nominar a estrutura, no sentido de esvaziá-la da carga epistemológica dos conceitos de "cultura material", "artefato" ou "objeto". Ainda que o título do artigo traga o conceito "artefato", o faz mais como categoria de análise no sentido de situar a casa como um "coisa" musealizada em museu arqueológico. Um "artefato".

6 Utilizaremos a palavra juruá, do léxico Mbyá Guarani, para designarmos o mundo não indigena, especificamente, neste caso, a ontologia moderna ocidental dominante. Os "brancos".

A pesquisa em andamento contempla a ida a campo, para entrevistar os construtores da casa dos índios do Marsul.
} 
Figura 2 - Tekoá Nhüu Porã

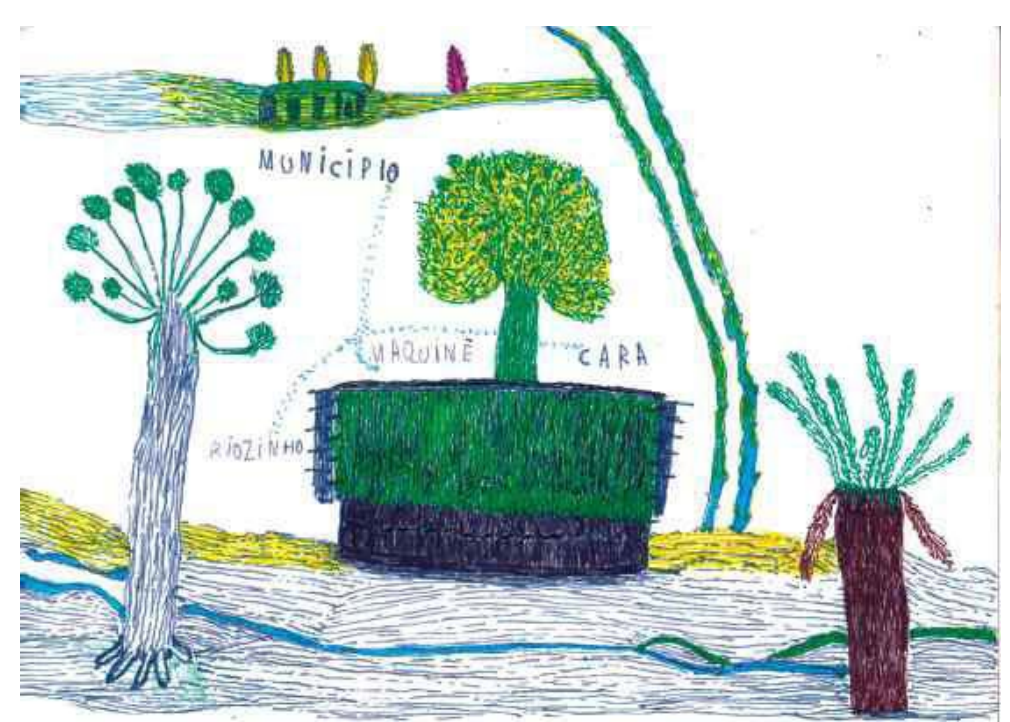

Fonte: José Verá Rodrigues, ASSECAN (2007).

No desenho realizado pelo lider espiritual Karaí (Figura 2), a casa é o tekoá ou o tekoá é uma grande casa. No desenho também aparecem as espécies arbóreas mais significativas, com destaque ao cedro, que se encontra ao centro enquanto à esquerda está a araucária e à direita o xaxim. O cedro é a última árvore feita por Ñanderu (principal divindade Mbyá), e representa Ñamandu (divindade associada ao sol) e está a associado à criação e à sustentação do mundo na ontologia Mbyá, por isso é preferido para o uso nas estruturas das casas tradicionais (PRUDENTE, 2007, p. 69).

O conceito "tekoá" pode ser visto, também, como um conceito ontologicamente situado, que remete a um lugar experienciado no mundo guarani. Melià (1989, 1990), diz que paisagem concebida como tekoá é um lugar sócio-político, cuja objetividade terrenal revela uma característica relacional de espaço físico-social. É o lugar onde se reproduz o modo de ser guarani, e é quando confrontado com o modo de ser ocidental que o ñandereko ou o teko ${ }^{8}$, são conceitos mobilizados tanto pelos guarani históricos quanto pelos guarani atuais para definir e defender seu modo de ser, que segundo o autor, coincide tanto os estudos da Arqueologia, da História e as observações etnográficas contemporâneas, a perspectiva que faz da terra, ou o espaço habitado, não apenas um simples meio de produção econômico (MELIȦ, 1990, p. 36).

O tekoá significa e produz ao mesmo tempo relações econômicas, relações sociais e organização político-religiosa essenciais para a vida guarani... Ainda que pareça um paralogismo, temos que. juntamente com os próprios dirigentes guarani, que sem tekoá não há teko (MELIÀ, 1990, p. 36).

As casas tradicionais são elementos vivos, com um ciclo de vida associado ao seu consumo e que é justificado e ordenado na cosmologia Mbyá. O solo, do lugar a ser instalada a oó, deve ser propício para cultivos tradicionais, sobretudo para o milho sagrado, o avaxi eté. A orientação solar deve ser considerada na implantação, pois o sol, Ñamandu, que alimenta a casa, nasce na morada de Karai (leste), passa pela morada de Jakairá (zênite) e se põe na morada de Tupã (oeste). O processo de construção é realizado em mutirão ritual, potirõ, que é organizado e custeado pela família que habitará a oó e centrado nas relações de parentesco e de reciprocidade Mbyá. A casa, quando pronta, recebe um ritual de iniciação, com festas e rezas, para que todas as espécies vegetais utilizadas, criem um único espírito (PRUDENTE, 2007, p. 138).

8 Teko, segundo Melià (1990, p. 36), a partir do Tesoro de la lengua guarani de Montoya (1639), significa "modo de ser, modo de estar, sistema, lei, cultura, norma, comportamento, hábito, condição, costume..." 
Ao analisarmos o processo de instalação da casa dos índios no Marsul, percebemos que esses aspectos não foram inteiramente observados pelos construtores. Obviamente, a escolha do lugar de instalação, fora do tekoá, no pátio de um museu, não contempla a condição de espaço Mbyá (o tekoá), tampouco um espaço propício ao cultivo do avaxi eté. A estrutura está isolada e desterritorializada. Quanto à orientação solar, a casa dos índios do Marsul está praticamente voltada para o norte, contrariando a orientação leste-oeste que apresentam as casas nos tekoá. Foram feitas cantorias no entorno da casa dos índios, nos dias do evento em 2002, no entanto não foi acesa a fogueira interna, que juntamente ao sol, Ñamandu, alimenta uma oó no tekoá, segundo os informantes de Prudente. A não utilização do cedro em sua estrutura, a partir da observação das fotografias, também se soma à descaracterização. Tendo em vista todas essas ausências de elementos que fariam a casa dos indios do Marsul uma oó, podemos dizer que esse esvaziamento teria sido intencional e calculado pelos Mbyá.

Buscando compreender no contexto de uma operação mercantil, recorremos a uma etnografia focada na produção e na circulação de objetos Mbyá, que dá conta que a reciprocidade se constitui na estrutura das relações sociais Mbyá, como ressalta Assis (2006), em sua tese de doutorado, analisando as comunidades Mbyá Guarani Tekoá Ka'agüy Pa'ũ e o Tekoá Guapo'y, comunidades vizinhas ao Tekoá Nhüu Porã, evidenciando o mborayu, o princípio da reciprocidade, que segundo a autora, muitas trocas de objetos feitas pelos Mbyá baseiam-se nesta premissa. "Uma constante etnográfica e histórica, que se aplica a todos os Guarani de todos os tempos é que vivem uma economia de reciprocidade" (MELIȦ, 1990, p. 45). A troca mercantil é uma forma de se relacionar com a alteridade, não limitando-se apenas ao âmbito econômico. Os objetos produzidos para a comercialização, o artesanato Mbyá usado como exemplo, são concebidos e produzidos para serem mercadorias, destinados à venda no mundo exterior, o mundo dos juruá, ainda que guardem significados culturais identitários
(ASSIS, 2006, p. 312). A casa dos índios do Marsul, poderiamos afirmar, por essa perspectiva que, embora carregue as características Mbyá, foi concebida e produzida pelos construtores como um objeto a ser vendido.

Contudo, para compreender como é ordenada essa relação comercial entre os Mbyá, descreveremos uma narrativa mítica feita pelo principal informante de Assis, Perumi, lider Mbyá, sobre a criação dos ajaka, cestos artesanais Guarani, que ocorreu conjuntamente com a criação do mundo pela segunda vez, por Ñanderu Tenonde, divindade primordial, que buscava criar um mundo com condições de existência aos seus filhos, os Mbyá. Nesse mundo recém-criado, havia Charĩa, um ser solitário, atrapalhado, uma divindade antitética a Ñanderu, que é o modelo divino da organização social Mbyá baseada na reciprocidade, mborayu.

Quando Ñanderu Tenonde estava quase concluindo a recriação do mundo, decidiu produzir um ajaka trançando fasquias de taquara. Para produzir um desenho, valeu-se de algumas fasquias mais escuras. A partir do contraste entre as fasquias que compõem a trama do trançado, produziu dois tipos de desenhos, denominados para pychyry/desenho corrido (para = adornado, desenhado; pychyry = corrido, em seqüência) e pira ryñykái ra anga/desenho representação do maxilar do peixe (pira rynykái = maxilar de peixe; ra'anga = imagem, representação).

[...] Observando o que Ñanderu havia feito, Charĩa resolve imitá-lo, mas como era de se esperar (pelas caracteristicas dessa divindade), ele produz vários ajaka e com trançados que formavam desenhos mais elaborados e detalhados do que aqueles originalmente feitos por Nanderu. Os ajaka de Charĩa apresentavam desenhos com motivos de Mbói Chinĩ ra'anga/representação da pele da cobra cascavel, Mbói Jarara ra'anga/da cobra jararaca e Tanambi Pepo ra'anga/ da asa de borboleta, mariposa (ASSIS 2006, p. 249, grifo do autor).

A partir deste fragmento do mito, podemos concluir, assim como afirma a autora, que os ajaka herdados de Ñanderu são feitos para uso próprio, enquanto os ajaka herdados de Charĩa, podem ser vendidos, estabelecendo uma dicotomia (Figura 3) relacionada aos ajaka, da qual resulta um ordenamento das relações de trocas o outro (ASSIS, 2006, p. 250). 
Figura 3 - Sequência de oposições

\section{Nós Ñanderu \\ Ajaka com motivos conotativos dicromia \\ Uso restrito \\ Troca dadivosa}

Fonte: Reprodução a partir de Assis (2006, p. 250).

De maneira análoga, podemos dizer que não apenas os ajaka fazem parte dessa dicotomia entre o nós e os outros. Poderíamos situar a casa dos indios do Marsul como sendo uma produção para juruá, para os outros. Portanto, esvaziada da sua ligação com Ñanderu e, por conseguinte, com o seu modo de ser, o ñandereko. Neste sentido, a casa dos índios, seria como um grande ajaka, sem associação com Charĩa, tampouco com Ñanderu, feita desde o início para a troca comercial. Uma grande peça de artesanato.

Notemos que, ainda que a casa tenha sido feita desde o início para comercialização, sem alguns elementos que só fariam sentido se estivessem em uma oó no tekoá, ela carrega elementos estruturantes da sociedade Mbyá, assim como os ajaka, e a troca comercial também se insere no princípio de reciprocidade, o mborayu. Entregando uma casa que foi construída por um mutirão, potirõ, como se fosse uma casa de moradia Mbyá, sendo possivel até acender fogueira no seu interior, como garantiu o líder Mbyá Avelino Gimenez à professora Zilá Kolling (KOLLING, 2018), fica implicita uma relação de reciprocidade, que entregou uma peça construida tradicionalmente da melhor maneira - uma caracteristica Mbyá em ser e fazer as coisas do jeito tradicional uma casa habitável, em troca de valores e de auxilios destinados à sustentabilidade do seu aldeamento. Sendo dessa forma, a casa dos indios um artefato aos olhos juruá, feita como artesanato a ser vendido, mas dotada de mborayu, o princípio de reciprocidade Mbyá.

\section{Considerações finais}

De fato, considerar as afirmações situadas ontologicamente, e levar a sério essas assertivas,

\section{Outros \\ Charia \\ Ajaka com motivos denotativos policromia \\ Uso amplo Troca mercantil}

tomando-as como conhecimentos tão válidos teoricamente quanto os conhecimentos antropológicos, uma simetria nos discursos, causa uma "virada" no pensamento sobre os estudos (ditos) culturais. Essa virada ontológica, se observada em perspectiva histórica, ganhou forma a partir da "angústia epistemológica dos antropólogos" que tensionou o rompimento com os dualismos cartesianos do pensamento moderno. A inversão entre as grandezas "natureza" $\mathrm{e}$ "cultura", suposta na nossa ontologia (moderna, ocidental e dominante), gerou um grande impasse, cujo equacionamento seria a tarefa da crítica antropológica direcionada aos próprios antropólogos e seus métodos. Em meios acadêmicos, há muitas dúvidas quanto à aplicabilidade de um multinaturalismo, ou de uma abordagem ontográfica quando afastada do mundo amerindio. Vimos que Holbraad, ao tratar conceitos de matriz africana como expressões de alteridade ontológica, o fez com maestria. A alteridade ontológica transcende espaços fisicos, provocando estranhamentos que surgem a partir de uma afirmação verbal ou da própria materialidade.

Considerar a alteridade ontológica nas abordagens direcionadas aos estudos das coisas, como percebemos pelo método ontográfico, é tratar de conceituações ontologicamente situadas. É "pensar através das coisas" com compromisso ontológico que exige uma abordagem através dos "mundos" para que haja compreensão entre os agentes. Conceitos homonimicos, ou aparentemente sinônimos, podem se manifestar ontologicamente distintos. Neste ponto, a virada ontológica poderia ser descrita como uma multiplicação de universos linguísticos. Assim, se ao tratar da alteridade como ontologia outra, poderiamos considerar 
os contextos outros, conceitos outros, epistemes outras etc. Com isso - não estou desconsiderando a Virada Ontológica enquanto virada, tampouco caindo no relativismo ao pluralizar a ontologia - podemos considerar a ontological turn como uma espécie de radicalização da própria linguistic turn. Pelo menos, caberia tal definição aos autores proponentes do método ontográfico. A leitura da cultura, proposta pelos pós-estruturalistas, deve ser feita considerando a semântica outra. A tradução, neste caso, como aponta Viveiros de Castro, é a arte de equacionar os equívocos resultantes de uma comparação translativa. Uma comparação entre a antropologia produzida pela ontologia ocidental, e a antropologia outra.

A "casa dos índios" do Marsul, entrou neste texto como exemplo de alteridade ontológica, que devido a sua desterritorialização, causou estranheza entre os mundos. Uma possibilidade analítica "pelos mundos", considerando que tratamos, na zona do equivoco, de uma comparação antropológica translativa. O fato de a "casa" não ser uma casa, tampouco uma oó, o que pôde ser percebido pelos esvaziamentos em sua construção, a denominamos com um artefato, que foi encomendado e pago por um museu. Como um objeto Mbyá, foi feita para juruá, sem os elementos de uma oó em um tekoá, despossuida de suas ligações com as divindades Mbyá. Entretanto, foi feita desde o início para ser destinada ao mundo exterior, tal como são feitos os ajaka pelos Mbya, porém sem carregar consigo elementos cosmológicos para além dos elementos construtivos. A "casa dos índios" do Marsul, foi um artefato ou uma instalação para a museografia no mundo ocidental e, pode ter sido uma grande peça de artesanato cuja comercialização foi pauta pelo principio de reciprocidade Mbya.

\section{Referências}

ALBERTI, Benjamin. MARSHALL, Yvonne. Local Theories and Conceptually Open-Ended Methodologies. Cambridge Archaeological Journal, [S. L.], v. 19, n. 3. p. 344-356, 2009. DOI: https://doi.org/10.1017/ S0959774309000535
APPADURAI, Arjun. A vida social das coisas: as mercadorias sob uma perspectiva cultural. Niteroi: Editora da UFF, 2008

ASSECAN (Associação Ecológica de Canela - Planalto das Araucárias). José Verá: Mbiá-Guarani. Projeto Mbiá-Guarani. Porto Alegre: ASSECAN, 2007.

ASSIS, Valéria Soares. Dádiva, mercadoria e pessoa: as trocas na constituição do mundo social Mbyá-Guarani. Tese de Doutorado, Porto Alegre: UFRGS, 2006.

BOURDIEU, Pierre. A economia das trocas simbólicas. 6. ed. São Paulo: Perpectiva, 2007.

GELL, Alfred. Arte e Agência: uma teoria antropológica. São Paulo: Ubu Editora, 2018. (Coleção Argonautas).

GONÇALVES, José Reginaldo Santos. Antropologia dos objetos: coleções, museus e patrimônio. Rio de Janeiro: IPHAN, 2007.

HENARE, A.; HOLBRAAD, Martin.; WASTELL, Sari. Introduction: Thinking through things. In: HENARE, Amiria J. M.; HOLBRAAD, Martin; WASTELL, Sari. Thinking through things: theorising artefacts ethnographically London: Routledge, 2007. p.1-31.

HOLBRAAD, Martin. Estimando a necessidade: os oráculos de ifá e a verdade em Havana. Mana, Rio de Janeiro, v. 9, n. 2, p. 39-77, oct. 2003. Disponivel em: http://www.scielo.br/scielo.php?script=sci_arttext\&pid=S0104=93132003000200002-\&lng=en\&nrmiso. Acesso em: 30 nov. 2018. DOl: http://dx.doi. org/10.1590/S0104-93132003000200002.

HOLBRAAD, Martin. Truth beyond doubt: Ifá oracles in Havana. HAU: Journal of Ethnographic Theory, IS. l.], v. 2, n. 1, p. 81-109, 2012. Disponivel em: https:// www.journals.uchicago.edu/doi/full/10.14318/ hau2.1.006. Acesso em: 30 nov. 2018

KOLLING, Zilá Regina. Entrevista concedida a Antonio C. Soares em 30/06/2018.

LATOUR, Bruno. Reagregando o social: uma introdução à teoria do Ator-Rede. Salvador: EDUFBA, 2012.

LIMA, Tânia Andrade. Cultura Material: a dimensão concreta das relações sociais. Boletim do Museu Paraense Emilio Goeldi: Ciências Humanas, Belém, v. 6, n. 1, p. 11-23, jan. /abr. 2011

MELIÀ, Bartomeu. El Guarani conquistado y reducido ensayos de etnohistória. Assunción: CEADUC, 1988

MELIȦ, Bartomeu. A terra sem mal dos Guarani: economia e profecia. Revista de Antropologia, São Paulo, 33, dez 1990. 33-46. Acesso em: 30 jun. 2019

MILLER, Daniel. Trecos, troços e coisas: estudos antropológicos sobre a cultura material. Rio de Janeiro: Zahar, 2013

PRUDENTE, Letícia T. Arquitetura Mbyá-Guarani na Mata Atlântica do Rio Grande do Sul: Estudo de Caso do Tekoá Nhüu Porã. Dissertação (Mestrado) -UFRGS, Porto Alegre, 2007. 
RÜSEN, Jörn. Reconstrução do passado. Teoria da história II: os principios da pesquisa histórica. Tradução de Asta-Rose Alcaide. Brasília: UnB, 2007.

SAHLINS, Marshall David. Cultura na prática. 2. ed. Rio de Janeiro: Editora UFRJ, 2007.

SANTOS, Maria Cristina dos; FELIPPE, Guilherme Galhegos. Apropriações possiveis de um protagonismo outro. Rev. Bras. Hist., São Paulo, v. 37, n. 76. p. 115-136, dez. 2017. http://dx.doi.org/10.1590/ 1806-93472017v37n76-06

SOARES, Antonio C. A Casa dos índios: a história de vida de um artefato. Mouseion, Canoas, n. 31, p.89-104, 25 fev. 2019. UNILASALLE. http://dx.doi. org/10.18316/mouseion.voi31.5225.

VIVEIROS DE CASTRO, Eduardo. Os pronomes cosmológicos e o perspectivismo amerindio. Mana, Rio de Janeiro, v. 2, n. 2, p. 115-144, Oct. 1996. Disponivel em: http://www.scielo.br/scielo.php?script=sci_arttext\&pid=S0104=93131996000200005-\&lng=en\&nrmiso. access on 30 Nov. 2018. http://dx.doi. org/10.1590/S0104-93131996000200005.

VIVEIROS DE CASTRO, Eduardo. O nativo relativo. Mana. Rio de Janeiro, v. 8, n. 1, p. 113-148, Apr. 2002 Disponivel em: http://dx.doi.org/10.1590/S010493132002000100005

VIVEIROS DE CASTRO, Eduardo. Perspectival Anthropology and the Method of Controlled Equivocation, Tipiti: Journal of the Society for the Anthropology of Lowland South America: Vol. 2: Iss. 1, Article 1. 2014. Acessivel em https://digitalcommons.trinity. edu/tipiti/vol2/iss1/1

VIVEIROS DE CASTRO, Eduardo. Perspectivismo e multinaturalismo na América indigena. O que nos faz pensar, [S.l.], v. 14, n. 18, p. 225-254, sep. 2004. ISSN 0104-6675. Disponivel em: http://www.oquenosfazpensar.fil.puc-rio.br/index.php/ognfp/article/ view/197. Acesso em: 30 nov. 2018.

\section{Endereço para correspondência}

Antonio Carlos Soares

Museu Arqueológico do Rio Grande do Sul - MARSUL

Av. Sebastião Amoretti, 6310

Km 04, 95611250

Taquara, RS, Brasil

\section{Antonio Carlos Soares}

Mestrando em História pela Pontificia Universidade Católica do Rio Grande do Sul (PUCRS, Porto Alegre, RS, Brasil). Historiador e arqueólogo do Museu Arqueológico do Rio Grande do Sul (MARSUL), Taquara, RS, Brasil. 